\title{
Application of Neural Network Technology in Welding Procedure Qualification for Joint
}

\author{
Ji'ai Xue, Weiping Ouyang*, Yannan Du and Huiqing Ouyang \\ No. 915 Jinshajiang Road Shanghai, China \\ ${ }^{*}$ Corresponding author
}

\begin{abstract}
Welding Procedure for joint has a very important position in the manufacture of all kinds of important products. Application of neural network technology could improve the existing in welding procedure qualification for joint process. It is shown that the yield strength of welded joint could be predicted effectively by using the welding parameters of welded joint, the temperature of the welding parameters and the heat treatment after welding as the input parameters by the neural network training. But the $P, B$ and $S$ element could be ignored in the process of predicting yield strength due to little influence on yield stress. The yield strength of steel could be increased by the increase of $C$ content, which could be decreased by the increase of the heat treatment temperature. Neural network model predicts the yield strength of materials with high accuracy, which could be utilized to the simulation of welding procedure qualification for joint.
\end{abstract}

Keywords—neural network; yield stress; welded joint

\section{INTRODUCTION}

Welding Procedure for joint has a very important position in the manufacture of all kinds of important products. There are many technological parameters affecting the mechanical properties of welded joints[1]. Welding procedure qualification for Joint should be carried out, when any important parameter changes, such as preheating temperature, heat treatment temperature, and welding line energy beyond the specified range[2]. It could spend large money and time in completing design and test of welding procedure for Joint and mechanical properties test of welded joints, which may cause delays in production. In order to address these problems, multiple regression, fuzzy mathematics and artificial intelligence expert system are used to try to evaluate welding procedure qualification for Joint instead of the conventional method. However, preheating and post-welding heat treatment specifications are closely related to the welding quality and the mechanical properties of welded joints. At the same time, the performances of the welded joint are affected directly by the chemical composition of the welded material and the chemical composition of the filler metal. The relationship between these factors and the mechanical properties of the joints is difficult to be clearly described by mathematical formulae, which is an insurmountable gap of the traditional method encountering. Neural network has the characteristics of strong nonlinear mapping, superior fault-tolerant performance and self-learning, which has been widely used in welding field[3]. The artificial neural network has obtained the ideal effect in welding process parameter design, welded joint performance estimation, spot welding quality control, MIG welding process control and HAZ performance prediction[4-6]. However, the existing research on mechanical performance prediction of fusion welded joint is faultiness, and the data samples adopted by the existing research institute are obtained by welding thermal simulation test, which could only predict the heat affected zone of thermal simulation, and not predict the whole welded joint. Therefore, the prediction results of neural network model are not enough to explain the mechanical properties of actual welded joints. It is of great practical value to use neural network to establish the prediction model of mechanical properties of welded joints.

In this paper, it is mainly about the application of the artificial neural network in mechanical behavior prediction of welded joint on the basis of the theory of neural network. The relation between welding factors such as chemical composition, heat treatment and welding procedure parameters and mechanical properties of welded joint. It is useful to identify the key parameters that affect the mechanical properties of the material, which is a new way to evaluate welding procedure qualification for joint.

\section{ARtificial NEURAL NetWORK}

Neural network modeling is the use of some structure and mechanism of human brain and human knowledge and experience. The neural network could learn from experience and deal with the complex process of nonlinear uncertain modeling of high dimension, such as welding production. Back propagationneural network (BP Neural Network), known as multi-layer feed forward neural network, is adopted in this system, which is a multi-layer network for weight training of nonlinear differentiable functions. Relationship between input and output of BP Neural Network is a highly non-linear mapping relationship. If the input and output node is $\mathrm{n}$ and $\mathrm{m}$ respectively, the network is a mapping of Euclidean Space from $n$ to $m$.

According to the principle of metallography and welding process characteristic, the input variables of neural network model including the chemical composition of welded joint, welding parameters, interpass temperature and heat treatment after welding, and output variables including four important mechanical properties: tensile strength, yield strength, elongation, reduction of area. Chemical composition includes conventional elements of steel, such as $\mathrm{C}, \mathrm{Si}, \mathrm{Mn}, \mathrm{S}, \mathrm{P}, \mathrm{Ni}, \mathrm{Cr}$, $\mathrm{Mo}, \mathrm{V}, \mathrm{Ti}, \mathrm{N}, \mathrm{Al}, \mathrm{B}, \mathrm{Sn}, \mathrm{Nb}$ and $\mathrm{Cu}$. The current type is composed of $\mathrm{AC}$ and $\mathrm{DC}$, and the current polarity is only 
divided into direct current straight polarity (DCSP) and direct current reverse polarity (DCRP). Therefore, 0 and 1 are respectively used to indicate DC and AC, which are also respectively represent DCSP and DCRP, as shown in Table 1.

\section{NEURAL NETWORK DATA ACQUISITION AND TRAINING}

The training of neural network requires a lot of experimental data, and the data must have a large coverage area so that the training model could be used. It's obviously seen that the number of initial input parameters for the model of yield strength training is 19. After continuous training comparison, the key influencing factors that affect the mechanical properties of welded joints can be determined. In the training process, the input and output data are converted to \pm 0.5 in (1). When the output value is predicted, it is converted back to the original value so as to compare the impact of each input parameter on the output value, while improving the efficiency of model training.

$$
x_{N}=\frac{x-x_{\min }}{x_{\max }-x_{\min }}-0.5
$$

Where: $\mathrm{X}_{\mathrm{N}}$ is the value of $\mathrm{X}$ after transformation. $\mathrm{Xmin}$ and $\mathrm{Xmax}$ are the maximum and minimum values of $\mathrm{X}$ respectively.

The neural network realizes the nonlinear mapping by training the sample data in the database. Each model trained could describe the characteristics of the model by using test error, perception level of noise, LPE, relationship between combination model number and error, predicted value obtained by training data, and predicted value obtained by test data. 100 submodels are trained at the same time each time, then they are combined in the order of LPE values from high to low, and then the optimal combination model number and the sub-model used in the combination model are got.

The number of input parameters used in training are large, and the impact of each parameter on the output value is also completely different. The effect of each parameter on yield strength of four submodels on manual arc welding obtained in the initial training is shown in Figure I. It could be seen that C, $\mathrm{Ni}, \mathrm{Cr}, \mathrm{Mo}, \mathrm{V}, \mathrm{Ti}$, welding line energy (inputheat) and interlayer temperature (temp) have a great influence on yield strength. Though Si, P, N and B element, current polarity, heat treatment after welding temperature $(\mathrm{P}-$ temp) and time $(\mathrm{P}$ time) impact on the output of the yield strength is lesser, these variables on the regulation of the output value has a certain effect. P, B, S have little effect, which could be ignored.

The data is divided into two parts. Half is used for the training model, and the other is for the test model. The prediction results are presented Figure II. It could be observed that the error of the predicted value of test data is larger than the predicted value of training data, which is controlled within a certain range of accuracy. So it could be considered that the training model has a better effect.
TABLE I. CURRENT TYPE AND CURRENT POLARITY

\begin{tabular}{|c|c|c|}
\hline Type & Current Type & Electrical Polarity \\
\hline DCSP & 0 & 0 \\
\hline DCRP & 0 & 1 \\
\hline AC & 1 & 2 \\
\hline
\end{tabular}

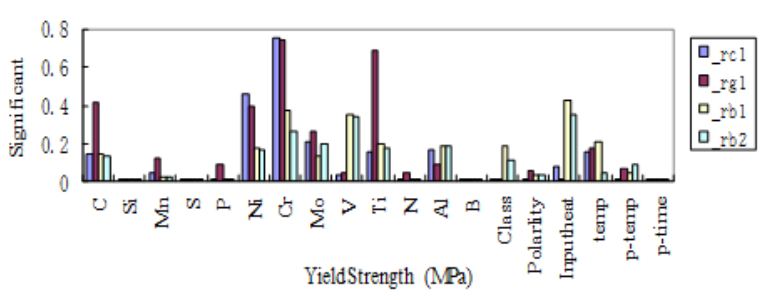

FIGURE I. INFLUENCE OF INPUT PARAMETERS ON YIELD STRENGTH
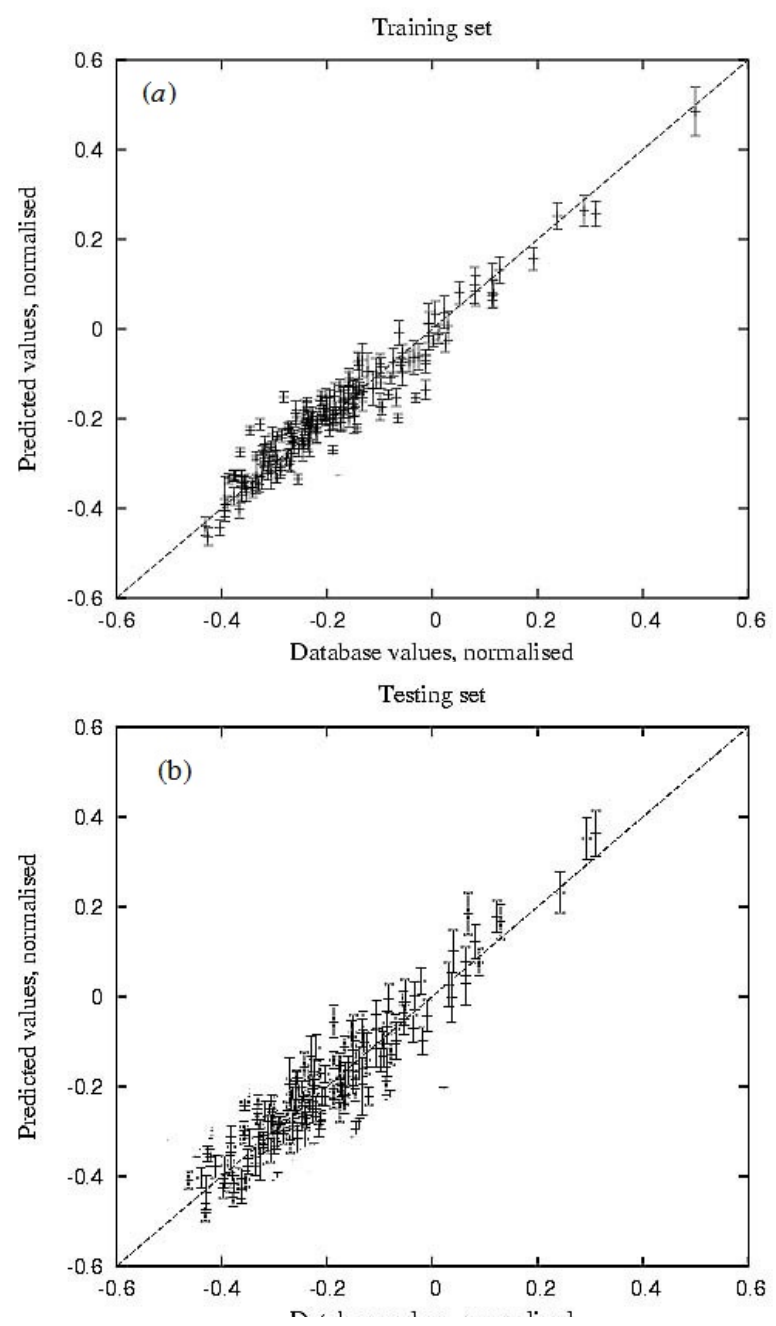

FIGURE II. TRAINING RESULTS OF BEST COMBINATION MODEL: (a) TRAINING DATA AND (b) TEST DATA 


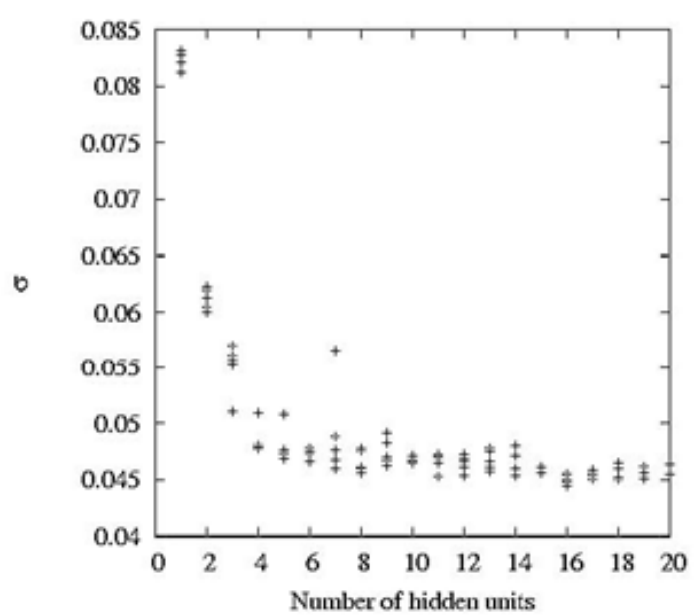

FIGURE III. RELATIONSHIP BETWEEN THE NOISE AND THE HIDDEN UNIT

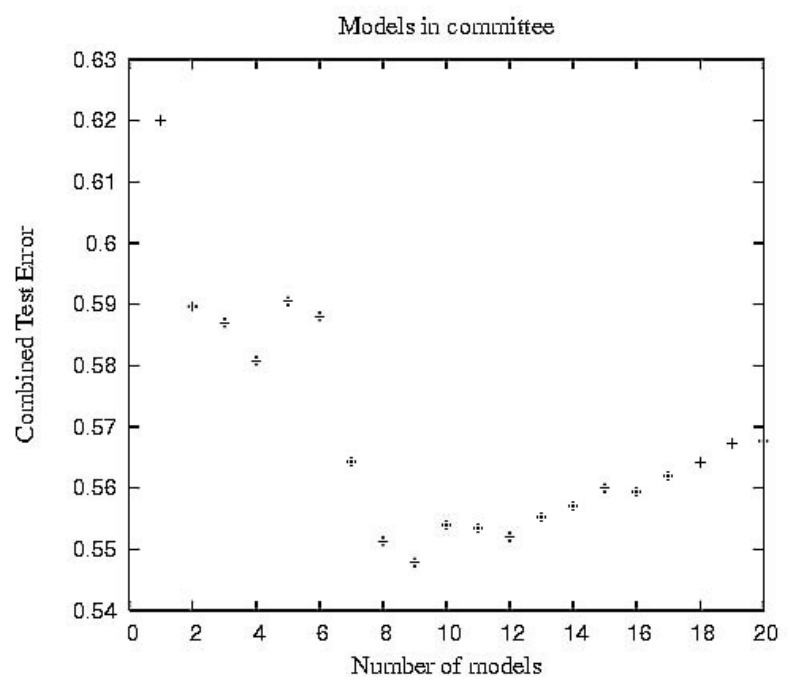

FIGURE IV. RELATIONSHIP BETWEEN THE MODEL ERROR AND THE MODEL NUMBER

The relationship between the noise and the hidden unit is shown in the Figure III. It could be observed that as the number of hidden units increases, the noise value becomes smaller and smaller. Relationship between the model error and the model number is displayed in the Figure IV. A model composed of nine sub-models with largest LPE owns the minimum error.

The effect of $\mathrm{C}$ element on yield strength was predicted with Si-0.26Mn-1.36V-0.0045Ti-29N-79Al-5 steel as shown in Figure V. It could be obviously seen that the yield strength increases with the increase of carbon content due to solid solution strengthening of $\mathrm{C}$ element. When $\mathrm{C}$ content is $0.077 \%$, the measured value of yield strength is $536 \mathrm{MPa}$, the predicted value of the neural network model is $521.52 \mathrm{MPa}$ and the error was $2.4 \%$. As shown in Figure VI, Si-0.26Mn-1.36V0.0045Ti-29N-79Al-5 steel is used to illustrate the effect of post-weld heat treatment temperature on yield strength. With the heat treatment after welding temperature increases, the yield strength is reduced. When after welding heat treatment temperature is $250 \quad \mathrm{C}$, the yield strength of the measured value is $536 \mathrm{MPa}$, the neural network model to predict a value of $523 \mathrm{MPa}$, the error is $2.4 \%$. The neural network model can effectively predict the change trend of yield strength of welded joint with parameters., and realize the effective simulation of welding procedure qualification for joint.

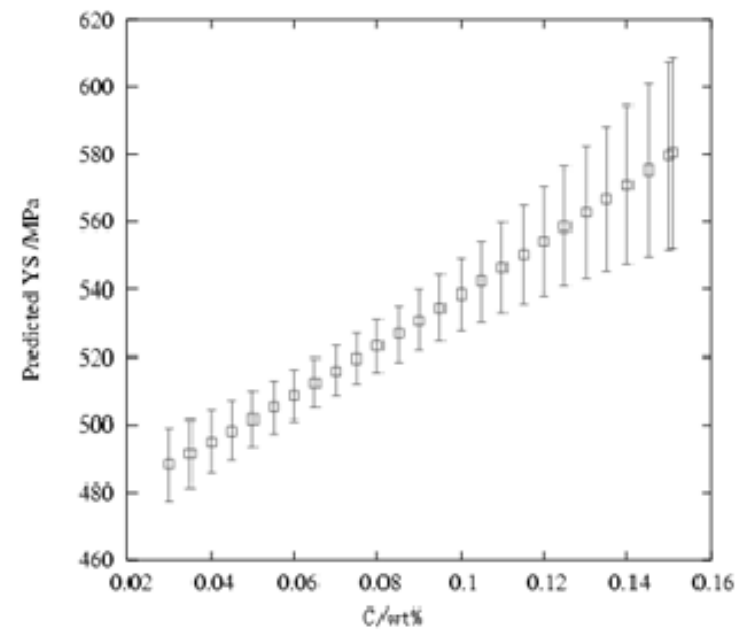

FIGURE V. EFFECT OF QUALITY FRACTION OF CARBONIUM ON YIELD STRENGTH

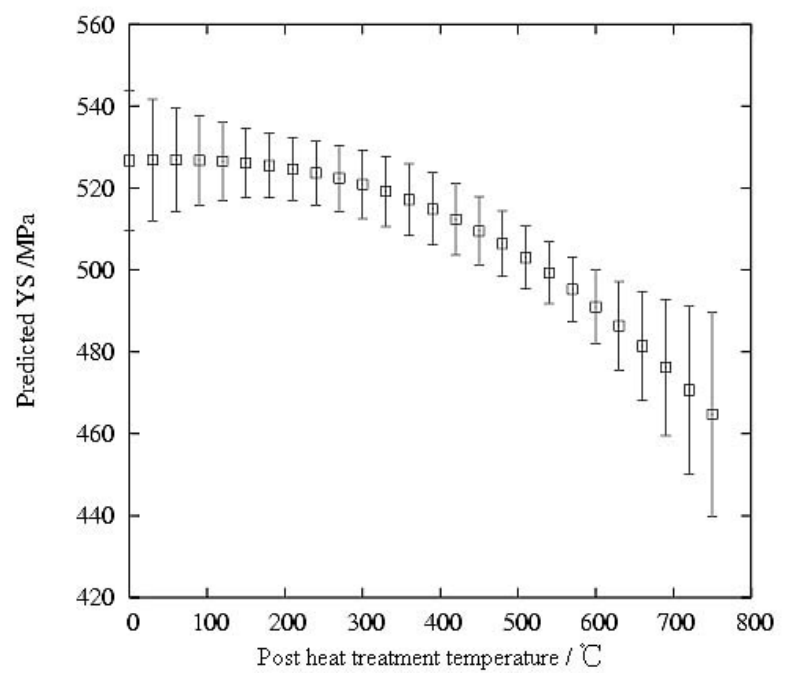

FIGURE VI. EFFECT OF HEAT TREATMENT TEMPERATURE ON YIELD STRENGTH 


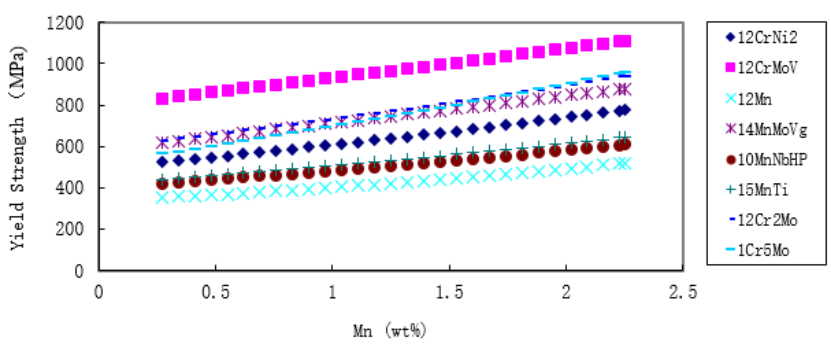

FIGURE VII. EFFECT OF HEAT TREATMENT TEMPERATURE ON YIELD STRENGTH

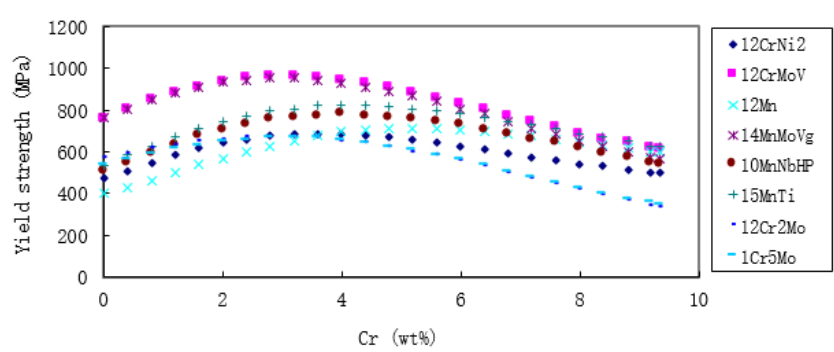

FIGURE VIII. EFFECT OF HEAT TREATMENT TEMPERATURE ON YIELD STRENGTH

As shown in Figure VII and VIII, it is the predicted results for several kinds of steel. The input parameters of neural network have different effects on yield strength. With the increase of $\mathrm{Mn}$ concentration, the yield strength of the steel could be increased, but the effect of Mn concentration on yield strength is very small. And the increase of the $\mathrm{Cr}$ element makes the yield strength of the steel increase first and then decrease. When the content of $\mathrm{Cr}$ is $3 \sim 4 \mathrm{wt} \%$, the yield strength is maximum.

\section{CONCLUSION}

It is mainly drawn as the following conclusions:

(1) The yield strength of welded joint could be predicted effectively by using the welding parameters of welded joint, the temperature of the welding parameters and the heat treatment after welding as the input parameters by the neural network training. As the number of hidden units increases, the noise value becomes smaller and smaller. A model composed of nine sub-models with largest LPE owns the minimum error.

(2) The P, B and S element has little influence on yield stress, which could be ignored in the process of predicting yield strength.

(3) The yield strength of steel could be increased by the increase of $\mathrm{C}$ content, which could be decreased by the increase of the heat treatment temperature.

(4) Neural network model predicts the yield strength of materials with high accuracy, which could be used for the simulation of welding procedure qualification for joint.

\section{REFERENCES}

[1] C.M. Estey, S.L. Cockcroft, D.M. Maijer and C. Hermesmann, "Constitutive behaviour of A356 during the quenching operation," Mater Sci. Eng., A, vol. 383, pp. 245-251, October 2004.
[2] L. Hu, Z.Y. Xiao and W.C. Fu, "Effect of manganese content on microstructure and properties of Fe-Cu-Mn-C sintering alloy,” Mater. Powder. Metall., vol. 6, pp. 821-826, June 2013.

[3] J. Clerk Maxwell, Neural Network: A Comprehensive Foundation, 2rd ed., vol. 1. Prentice Hall PTR, 1994, pp.1-10.

[4] L.M. Liu, M.L. Zhu, J.T. Niu and Z.D.Zhang, "Predicting effects of diffusion welding parameters on welded joint properties by artificial neural network,” T Nonferr Metal Soc., vol. 11, pp. 475-478, March 2001.

[5] B. Acherjee, S Mondal, B. Tudu and D. Misra, "Application of artificial neural network for predicting weld quality in laser transmission welding of thermoplastics,” Appl. Soft. Comput. J., vol. 11, pp. 2548-2555, March 2011.

[6] C. Ye, Z. Yang and Y. Hao, "Calculation and prediction of the bingham yield stress using BP neural network,” Hen. Sci., vol. 121, pp. 113-118, April 2009.. 